\title{
GAIA Level 2b Assessment of Gestational Age
}

National Cancer Institute

\section{Source}

National Cancer Institute. GAIA Level 2b Assessment of Gestational Age. NCI Thesaurus. Code C128015.

GAIA Level 2b Assessment of Gestational Age is defined by the following criteria: uncertain last menstrual period (LMP) date with second trimester scan (14 0/7 weeks to 27 6/7 weeks). 